This document is published in:

Materials and Design, Vol. 60 (2014), pp. 226-232

DOI: http://dx.doi.org/10.1016/j.matdes.2014.04.005

(C) 2014 Elsevier Ltd. 


\section{Accepted Manuscript}

Powder Metallurgy CP-Ti Performances: Hydride-DeHydride vs. Sponge

L. Bolzoni, E.M. Ruiz-Navas, E. Gordo

PII:

S0261-3069(14)00273-8

DOI:

http://dx.doi.org/10.1016/j.matdes.2014.04.005

Reference:

JMAD 6396

To appear in:

Materials and Design

Received Date: $\quad 28$ January 2014

Accepted Date: $\quad 1$ April 2014

Please cite this article as: Bolzoni, L., Ruiz-Navas, E.M., Gordo, E., Powder Metallurgy CP-Ti Performances: Hydride-DeHydride vs. Sponge, Materials and Design (2014), doi: http://dx.doi.org/10.1016/j.matdes.2014.04.005

This is a PDF file of an unedited manuscript that has been accepted for publication. As a service to our customers we are providing this early version of the manuscript. The manuscript will undergo copyediting, typesetting, and review of the resulting proof before it is published in its final form. Please note that during the production process errors may be discovered which could affect the content, and all legal disclaimers that apply to the journal pertain. 


\title{
Powder Metallurgy CP-Ti Performances: Hydride-DeHydride vs. Sponge
}

\author{
L. Bolzoni*, E.M. Ruiz-Navas, E. Gordo
}

Departamento de Ciencia e Ingeniería de Materiales e Ingeniería Química Universidad Carlos III de Madrid

Avda. de la Universidad, 30, 28911 Leganés (Madrid), Spain

*e-mail: bolzoni.leandro@gmail.com, lbolzoni@ing.uc3m.es, +34916249482

\begin{abstract}
Titanium is characterised by two contrasting aspects: outstanding combination of properties and high production costs which confine its application to high demanding sectors. The employment of powder metallurgy $(\mathrm{P} / \mathrm{M})$ techniques is one creative alternative to lower the final costs of titanium products due to some intrinsic advantages of $\mathrm{P} / \mathrm{M}$ such as high yield of material and limited machining requirement. In this work the performances of HydrideDeHydride (HDH) and sponge elemental titanium products obtained by cold uniaxial pressing and sintering are compared. It is found that the two materials achieved similar relative density values but HDH shows much better mechanical performances.
\end{abstract}

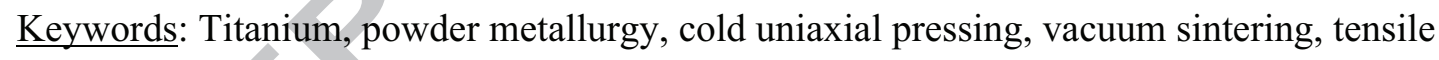
properties, dynamic Young modulus

\section{Introduction}

Titanium is considered a lightweight metal because has lower density $\left(\rho_{\mathrm{Ti}}=4.51 \mathrm{~g} / \mathrm{cm}^{3}\right)$ than steel $\left(\rho_{\mathrm{Fe}}=7.80 \mathrm{~g} / \mathrm{cm}^{3}\right)$, which is approximately $60 \%$ of the value of common steels. Although the lightness is one of the main advantage of titanium, this material is also characterised by other properties relevant from a technological point of view such as good mechanical properties (which also maintained up to relatively high temperatures), biocompatibility and excellent corrosion resistance in many different aggressive environments 
$[1,2]$. Despite of this combination of characteristics, titanium and its alloys have been primarily employed in the aerospace and aeronautical industries which made its final cost significantly changing as a function of the fluctuation of the demand of these sectors $[3,4]$. The fact that the employment of titanium was, and it is still mainly, limited to high demanding sectors, where the higher final cost in comparison to other competing metals is not a restricting factor, is due to the electronic structure of titanium. Specifically, titanium is an electropositive element of the IV group of the periodic table characterised by very high chemical reactivity with most of the other elements of the periodic table. Consequently, titanium easily reacts with interstitial elements and especially with oxygen, forming a passivation layer. The presence of this outer layer makes difficult the extraction of titanium in metallic form; extraction which is mainly still done by means of the Kroll process [5-7] although recently some new or upgraded processes have been proposed [6-11]. It is worth mentioning that the main product of the Kroll process is titanium in the form of sponge powder. The high reactivity of titanium, which increases with the temperature and it is significantly higher for the molten metal, also favours its reaction with the cast house tools, like moulds which are, commonly, oxide-based ceramics. The outcome of this interaction is the formation of a brittle surface layer, called $\alpha$-case $[12,13]$, which has to be mechanically or chemically removed. Another important feature of titanium is its low thermal conductivity which makes its machining rather complicated. The development of new extraction processes are not the only alternative to decrease the final production costs of titanium products. This can actually also be achieved by the employment of creative fabrication methods [14]. Powder metallurgy $(\mathrm{P} / \mathrm{M})$ techniques offer intrinsic advantages over the traditional metallurgy route which are very important in the case of titanium and its alloys. In particular, $\mathrm{P} / \mathrm{M}$ processes are characterised by very high employed to scrap metal ratio (i.e. high yield of expensive material), they are near-shape or near-net-shape methods which prevent or significantly limit the need of machining [15] (i.e. lower fabrication costs and avoidance of 
titanium machining related problems) and they are solid state techniques (i.e. lower reactivity with the fabrication tools). Both conventional [16-18] and advanced [19-21] P/M techniques have been considered to obtain dense and porous titanium products $[17,22]$ where the Ti-6Al$4 \mathrm{~V}$ alloy is the most common one [23-25]. The aim of this investigation is to compare the performances of elemental titanium products made starting from hydride-dehydride (HDH) and sponge powders. Specifically, the powders are shaped by means of the conventional P/M route of cold uniaxial press and vacuum sinter in the $1250^{\circ} \mathrm{C}-1350^{\circ} \mathrm{C}$ sintering temperature window. Physical properties, chemical analysis, mechanical behaviour and microstructure characterisation are discussed in detail and correlated between them in order to gain a full understanding of the behaviour of the materials studied.

\section{Experimental Procedure}

The starting powders used in the study were a hydride-dehydride (HDH) elemental titanium powder supplied by GfE and a sponge elemental titanium powder purchased from AEE. Basic features of the starting powders are reported in Table 1.

From the features of the staring powder reported in Table 1, it can be seen that the powder morphology is the consequence of the fabrication method. Specifically, Ti-HDH is characterised by an irregular morphology because it is produced by a comminution process. More in detail, in the HDH process titanium is hydrogenated at high temperature in order to dissolved a great quantity of hydrogen as solid solution into the titanium lattice and, therefore, make it completely brittle. Afterwards, titanium is crushed into briquettes and milled to reduce its particle size to the desired level. Finally, the powder is heat treated at high temperature under high vacuum in order to eliminate the dissolved hydrogen. In the case of Ti-Sponge, the powder is directly obtained by means of the Kroll's process where after different steps to eliminate the impurities and to form $\mathrm{TiCl}_{4}$ by reacting titanium with chlorine, sponge titanium powder is precipitated by using magnesium. In the conventional 
metallurgical route, the titanium sponge powder is milled and shaped into the desired semifinished product (such as ingots) by means of processes like Vacuum Arc Remelting (VAR) [26] or Electron Beam Cold Hearth Melting (EBCHM) [27]. Both the irregular and the sponge morphology are ideal for their processing by means of the cheapest $\mathrm{P} / \mathrm{M}$ route of cold uniaxial pressing and sintering. In particular, the powder particles can form mechanical interlocking among them by rearrangement and plastic deformation which are much needed to assure the handling of the pressed (green) components without fracture [28, 29]. Concerning the maximum particle size of the powders, Ti-HDH has relatively bigger maximum particle size in comparison to Ti-Sponge and this will influence the behaviour during the sintering step and, thus, the final properties achieved. This is because the smaller the particle size the greater the specific surface area of the powder particles where the reduction of this surface energy is the main driving force governing the sintering of a material. Base on this premise and giving that the two powders are pressed at the same level of uniaxial pressure, Ti-Sponge should undergo a greater densification. Nevertheless, a smaller particle size corresponds also to a greater amount of atmospheric gases adsorbed into the surface of the powder particle. In the case of titanium, the molecules adsorbed tend to diffuse inwards leading to the embrittlement of the material. As it can be seen from Table 1, Ti-HDH has similar purity with respect to Ti-Sponge as per Suppliers specifications.

Green samples were obtained by means of pressing of the starting powder with a uniaxial press and a floating die whose walls were lubricated with zinc stearate. Purposely, no lubricant was added to the titanium powder in order to consistently avoid their contamination. The floating die employed permitted to produce samples with the geometry (손 B925) required to perform tensile tests. The uniaxial pressure applied to shape the powders was set to $700 \mathrm{MPa}$. The sintering step was done in a tubular high-vacuum furnace keeping a minimum vacuum level of $10^{-5} \mathrm{mbar}$ and the heating and cooling rates constant at $5^{\circ} \mathrm{C} / \mathrm{min}$. Sintering temperatures variable between $1250^{\circ} \mathrm{C}$ and $1350^{\circ} \mathrm{C}$ and processing time of 2 hours 
were used during the work to study the influence of the temperature on the final properties of the titanium specimens. The dimensions (e.g. thickness) of the samples before and after sintering were measured by means of a 3-decimals micrometer to calculate the relative percent change. The values of the density of green $\left(\rho_{\text {green }}\right)$ and sintered $\left(\rho_{\text {sintered }}\right)$ samples and the nominal value of the density of titanium $\left(\rho_{\text {nominal }}: 4.51 \mathrm{~g} / \mathrm{cm}^{3}\right.$ [30]) were used to estimate the densification $(\Psi)$ of the material as per equation 1 :

$$
\Psi=\frac{\left(\rho_{\text {sintered }}-\rho_{\text {green }}\right)}{\left(\rho_{\text {nomimal }}-\rho_{\text {green }}\right)} * 100[\%]
$$

where: $\rho_{\text {green }}$ was calculated at the ratio between mass and volume of the green samples whilst $\rho_{\text {sintered }}$ was experimentally obtained by water-displacement measurements sealing the surface of the sintered specimens with a lacquer.

The values of the relative density $\left(\rho_{\text {rel }}\right)$ of the sintered samples was computed as the ratio between $\rho_{\text {sintered }}$ and $\rho_{\text {nominal. }}$ The analysis of the microstructure was performed in a PhilipsXL30 SEM and for the that the samples were grinded with SiC papers, polished with alumina and etched with Kroll reactant (i.e. a mixture of hydrofluoric and nitric acids plus distilled water). It is well-known that the total amount of interstitial elements dissolved in titanium highly influences its mechanical performance, therefore the contents of oxygen and nitrogen (ASTM: E1409) were measured in a LECO TC-500. Tensile tests (소M: E8) using crosshead speed of $1 \mathrm{~mm} / \mathrm{min}$ were done using a MicroTest universal machine. The deformation of the samples was determined on the base of the data acquired by means of a DD1-type extensometer. Because titanium is commonly employed to fabricate biomedical prostheses, the Young modulus of the most promising materials was obtained by ultrasonic measurements. Specifically, the so-called dynamic Young modulus was calculated as a 
function of $\rho_{\text {sintered }}$ and the speed of sound (v) in the materials (which was measured with a Grindosonic transducer) as per equation 2:

$$
v=\sqrt{\frac{E}{\rho_{\text {sintered }}}}
$$

Finally, Vickers hardness measurements were performed on the cross-sections using a universal hardness tester (Wilson Wolpert).

\section{Results and Discussion}

The variation of the thickness induced by the sintering of the green samples, which is representative of the other dimensions, is plotted versus the sintering temperature in Figure 1. From the data displayed in Figure 1, it can be seen that both types of powders undergo a negative variation of the thickness which indicates that, actually, the samples shrink during sintering. Moreover, the shrinkage increases along with the sintering temperature reaching the highest values at $1350^{\circ} \mathrm{C}$. More in detail, the shrinkage experienced by samples made out of the Ti-HDH powder increases homogeneously of approximately $0.15 \%$ for an increment of the processing temperature of $50^{\circ} \mathrm{C}$. Conversely, in the case of Ti-Sponge specimens, the increment of shrinkage when increasing the sintering temperature from $1250^{\circ} \mathrm{C}$ to $1300^{\circ} \mathrm{C}$ (almost $0.3 \%$ ) is the double of that from $1300^{\circ} \mathrm{C}$ to $1350^{\circ} \mathrm{C}$. From this difference it is expected that the samples undergo a higher densification at the lower sintering temperature whilst at the higher temperature a greater part of the thermodynamics energy is invested in grain growth and pores coarsening rather than in the densification of the material. By the comparison of the behaviour of the two elemental titanium powders, it can be noticed that Ti-HDH samples are characterised by almost half of the shrinkage with respect to Ti-Sponge specimens, approximately $3 \%$ lower. This difference is due to the combined effect of the finer particle size distribution of the Ti-Sponge powder and the lower level of green density achieved after compaction. Specifically, the mean value of the green density of Ti-HDH and Ti-Sponge 
components is equal to $84.77 \pm 0.83 \%$ and $79.82 \pm 0.70 \%$, respectively. The lower green density of the Ti-Sponge powder is due to the difference in morphology and purity in comparison to Ti-HDH, where the greater the amount of interstitials dissolved the harder the powder and the more difficult to press it.

The variation of the densification parameter and of the relative density with the sintering temperature are shown in Figure 2.

From the data of the densification parameters plotted in Figure 2 a) it can be seen that the densification of the samples increases with the increment of the sintering temperature which is in agreement with the shrinkage of the samples. In particular, the increment of the densification of the Ti-HDH samples with the processing temperature seems quite linear whilst for the Ti-Sponge specimens the greater densification takes place when increasing the temperature from $1250^{\circ} \mathrm{C}$ to $1300^{\circ} \mathrm{C}$. This behaviour is coherent and it was already be supposed on the base of the shrinkage data (Figure 1). Once again, the final values regarding the Ti-HDH components are much lower than those of the Ti-Sponge specimens (around $25 \%)$. The greater densification of the Ti-Sponge powder is due to the finer particle size and, thus, it comes to be a greater driving force for the reduction of the specific surface area which the phenomena that governs sintering. Concerning the relative density data (Figure $2 \mathrm{~b}$ ), it is interesting to note that this properties increases with the increment of the sintering temperature but the difference between the two elemental titanium powders is not that significant. Specifically, the relative density of Ti-HDH samples increases from $96 \%$ to 96.8\% whilst that of the Ti-Sponge specimens from $96.1 \%$ to $97.4 \%$ with the processing temperature. The fact that the two types of powders reach very similar final relative density values is due to the compromise between the higher compressibility of the Ti-HDH powder (i.e. higher green density) and the finer particle size distribution of the Ti-Sponge powder (i.e. greater driving force). Conversely to the shrinkage and the densification, Ti-Sponge components experience the greatest variation when raising the sintering temperature from 
$1300^{\circ} \mathrm{C}$ to $1350^{\circ} \mathrm{C}$. This behaviour is a consequence of the fact that at the highest temperature considered in this study a greater amount of energy is spent in the movement of the pores rather than on the densification. The movement of the pores, especially along the grain boundaries or the original boundaries between the powder particles leads to their coalescence and, therefore, the coarsening of the size of the residual porosity despite the fact that its total amount is reduced. This behaviour indicates that the material is, actually, in the third or final stage of sintering [31].

The evolution of the microstructural features (i.e. grain size and porosity) with the sintering temperature is illustrated by means of the SEM micrographs reported in Figure 3. From the SEM micrographs shown in Figure 3, it can be seen the microstructure of both sintered elemental titanium samples is composed of grains of the alpha phase because the alloy was slow cooled from a temperature above the allotropic transformation temperature $\left(950^{\circ} \mathrm{C}\right.$ for $\mathrm{CP}-\mathrm{Ti}$ grade 4 [30]). Therefore, the material at high temperature (during sintering) is characterised by the body-centred cubic lattice but during the cooling the atoms move back to the positions of the hexagonal lattice typical of the alpha phase of titanium. From the micrographs, it can also be noticed that the mean alpha grain size becomes bigger with the increment of the sintering temperature due to the higher thermal energy available in the system for grain growth. The grain growth seems actually more pronounced when raising the sintering temperature from $1300^{\circ} \mathrm{C}$ to $1350^{\circ} \mathrm{C}$ rather than from $1250^{\circ} \mathrm{C}$ to $1300^{\circ} \mathrm{C}$ in agreement with the densification parameter (Figure 2 a). The other features characterising the microstructure is the residual porosity and it can be seen that its volumetric percentage decreases with the increment of the processing temperature as expected from the relative density data (Figure $2 \mathrm{~b}$ ). Furthermore, in the sintering window considered in this work, the pores are mainly isolated and spherical, even though some elongated pores can be seen, and the average pore size increases with the processing temperature. The presence of irregular pores and the increment of the pore size is because during the third stage of sintering, after 
that the interparticle boundaries had disappeared, the pores tend to coalesce reducing their percentage but increasing the size of the remaining pores (i.e. final stage of sintering). By comparing the micrographs of the two elemental titanium powders, no significant differences can be highlighted despite the fact that Ti-Sponge powder is characterised by finer particle size distribution.

Table 2 shows the results of the chemical analysis (i.e. oxygen and nitrogen contents) carried out on sintered samples.

From the data of the chemical analysis of the sintered samples reported in Table 2, it can be seen that both the amount of oxygen and nitrogen dissolved by the specimens increases with the sintering temperature with the exception of the Ti-HDH components sintered at $1350^{\circ} \mathrm{C}$ whose total interstitials content is somewhat lower than that of the samples processed at $1300^{\circ} \mathrm{C}$. More in detail, the increment of oxygen and nitrogen of Ti-HDH is not that significant because it is at maximum $0.02 \mathrm{wt} . \%$ and $0.03 \mathrm{wt} . \%$ for oxygen and nitrogen, respectively. In the case of the Ti-Sponge products, the increment of both oxygen and nitrogen is continuous and much more marked although the greatest variation happens when increasing the processing temperature from $1250^{\circ} \mathrm{C}$ to $1300^{\circ} \mathrm{C}$. The faster diffusion of interstitial elements and the much greater final contents of Ti-Sponge specimens with respect to Ti-HDH samples is primarily a consequence of the finer particle size of Ti-Sponge powder. From the data shown in Table 2 it can also be noticed that there is some oxygen and nitrogen contamination in comparison to the amount specified by the Suppliers (Table 1). The contamination of the powders derives from different sources such as handling of the powders, molecules adsorbed into the surface of the powder particles, air trapped in the porosity of the green samples and residual gases present in the tubular furnace used to sintered the materials. These aspects are also relevant to explain the differences between samples made out of the same material but processed under different conditions (i.e. higher sintering temperature favours the inwards diffusion of interstitials present in the surface). It is worth mentioning 
that, in general, the Ti-HDH samples respect the limit specified for ASTM titanium grade 4 [30] obtained by means of the conventional metallurgical route (Table 2).

Representative examples of tensile stress-strain behaviour of the Ti-HDH and Ti-Sponge samples $\left(1250^{\circ} \mathrm{C}\right)$ under a tensile uniaxial load are shown in Figure 4.

From the stress-strain curves of Figure 4, it can be seen that both Ti-HDH and Ti-Sponge elemental titanium sintered components share similar elastic behaviour because the curves overlap. Nevertheless, Ti-HDH samples deforms elastically up to approximately $450 \mathrm{MPa}$ and then starts to deform plastically whereas Ti-Sponge specimens deform elastically up to a stress of about $550 \mathrm{MPa}$ but then suddenly fail practically without plastic deformation. The precocious failure of the Ti-Sponge products as well as their higher yield strength is mainly due to the greater amount of interstitials dissolved because oxygen and nitrogen strengthens and embrittles titanium [32, 33].

Ultimate tensile strength (UTS) and strain mean values obtained from, at least three sintered samples, are plotted in Figure 5.

As it can be seen in Figure 5, the UTS of Ti-HDH samples remains approximately constant at $580( \pm 15) \mathrm{MPa}$ whilst that of Ti-Sponge specimens significantly decreases with the increment of the sintering temperature. In the case of Ti-HDH, the strength of the samples sintered in the $1250-1350^{\circ} \mathrm{C}$ temperature range is almost invariant due to the fact that the effect of the reduction of the residual porosity (i.e. higher relative density), the slight increment of interstitials contents and the grain growth experienced by the material processed at higher temperature perfectly compensate themselves. Having similar relative density and microstructural features, Ti-Sponge specimens should be characterised by, at least, comparable strength to that of Ti-HDH samples if not higher due to the greater amount of interstitial elements dissolved, which is the expected behaviour for wrought material [32-34]. Nevertheless, as shown in Figure 5 this comes not the be the case for $\mathrm{P} / \mathrm{M}$ products indicating that either after a certain percentage (which can be estimated to be around $0.7 \mathrm{wt} . \%$ of 
oxygen) the interstitials embrittle significantly the material leading to a loss of strength due to premature failure or that the strengthening effect typical of wrought titanium alloys is not taking place for $\mathrm{P} / \mathrm{M}$ parts. The comparison of the strength obtained in $\mathrm{P} / \mathrm{M}$ products with the that of wrought CP-Ti grade 4 (550 MPa [30]) seems to support the first of the two hypotheses because P/M samples and, especially the ones made out of the Ti-HDH powder, have similar or higher UTS despite of the presence of the residual pores which act as stress intensification sites. Actually, Ti-HDH samples have similar chemical composition but a little bit higher strength than wrought titanium most probably due to the smaller grain size of $\mathrm{P} / \mathrm{M}$ components. The UTS values shown in Figure 5 are also comparable to the value found by Ivasishin et al. using an electrolytic titanium powder (550-570 MPa) [35]. Concerning the ductility of the $\mathrm{P} / \mathrm{M}$ elemental titanium samples (Figure 5), the strain at fracture is almost constant independently of the sintering temperature employed to process the green parts. Once again, in the case of the Ti-HDH samples, the effects of the features of the microconstituents (i.e. mean alpha grain size and porosity characteristics), the level of relative density achieved and the total amount of interstitials dissolved are in equilibrium and the strain remains constant at around 10\%. Furthermore, the combination of these aspects for each specific samples leads also to an important deviation of the mean value found. In the case of Ti-Sponge specimens the strain mean value is always lower than $1 \%$ due to the significant embrittlement of the material by the interstitials. This factor is also the responsible for the considerable difference between the performances in terms of ductility of the two materials studied. The combined effect of high interstitials and residual porosity is detrimental for the ductility of Ti-Sponge specimens which, consequently, is much lower with respect to that of the wrought CP-Ti grade 4 (i.e. 15\% [30]). Thought comparable, the strain at fracture values for Ti-HDH samples are still lower than the value of the wrought material due to the presence of the residual porosity which acts as crack initiation sites. The fractographic study carried out on the fracture surface of tensile samples (micrographs not reported for brevity) 
reveals that the main failure mode of the materials is due to the presence of the residual porosity (i.e. pore-assisted fracture). Nonetheless, the dimples generated from the pores are much more deformed in the case of Ti-HDH samples with respect to Ti-Sponge specimens due to the fact that these last do not undergo significant plastic deformation.

The results of the dynamic elastic modulus measurements carried out on the most promising material (i.e. Ti-HDH) are shown in Table 3.

The values of the dynamic elastic modulus measurements (Table 3) carried out on Ti-HDH elemental titanium samples result to be quite similar for the three sintering temperatures. The individual values obtained are in the order of $100 \mathrm{MPa}$ giving a mean value of $104 \pm 9 \mathrm{GPa}$ which is very similar to the typical value of $105 \mathrm{GPa}$ of wrought titanium grade 4 [30]. This indicates that there is not a great (and clear) influence from the level of relative density obtained (i.e. $3-4 \%$ of residual porosity) most probably because the pores structure is mainly constituted of isolated and spherical pores (Figure 3).

The results of the Vickers hardness measurements carried out are reported in Figure 6. As it can be seen in Figure 6, the hardness of both Ti-HDH and Ti-Sponge sintered samples increases with the sintering temperature which is the expected behaviour for $\mathrm{P} / \mathrm{M}$ components. However, once again, the two materials have dissimilarities because the mechanical properties of titanium are highly influenced by interstitials $[32,33]$. Specifically, the hardness of Ti-HDH samples increases more when the sintering temperature is raised from $1250^{\circ} \mathrm{C}$ to $1300^{\circ} \mathrm{C}$ albeit of the linear increment of the relative density (Figure 2). This behaviour can be explained on the base of the fact that the samples sintered at $1350^{\circ} \mathrm{C}$ have lower amount of interstitials dissolved (Table 2). In the case of Ti-Sponge specimens, the increment in hardness is more linear due to the fact that the greatest increment of relative density is detected from $1300^{\circ} \mathrm{C}$ to $1350^{\circ} \mathrm{C}$ which compensates for the lower increment of interstitials shown in Table 2. The fact that the total amount of interstitial elements present in titanium greatly affect the mechanical properties and, especially, the hardness is confirmed by 
the fact that Ti-Sponge specimens are characterised by a much higher Vickers hardness with respect to Ti-HDH samples despite of the comparable relative density achieved. In particular, Ti-HDH samples $(\mathrm{O} \sim 0.40$ wt. $\%$ and $\mathrm{N} \sim 0.020$ wt. $\%)$ show values around $200( \pm 10) \mathrm{HV}$ whilst the hardness of Ti-Sponge specimens ( $\mathrm{O} \geq 0.67 \mathrm{wt} . \%$ and $\mathrm{N} \geq 0.060$ wt. $\%)$ ranges between $300 \mathrm{HV}$ and $330 \mathrm{HV}$. The higher amount of interstitials is also responsible of the fact that Ti-Sponge products are harder than wrought Ti grade 4 (253 HV on annealed state) [30] though of the presence of the residual porosity as microstructural feature. Actually, the effect of the residual porosity can be highlighted by comparing the hardness values of Ti-HDH with the wrought material because they have similar chemical analysis but different level of relative density (i.e. wrought titanium is supposed to be pore free, $100 \%$ of relative density).

\section{Conclusions}

Fro this study it can be concluded that hydride-dehydride (HDH) elemental titanium powder are a much more suitable alternative rather than sponge powders in order to produce powder metallurgy $(\mathrm{P} / \mathrm{M})$ components. Specifically, the processing of HDH by the conventional and cheapest $\mathrm{P} / \mathrm{M}$ route of cold uniaxial pressing and sintering permits to obtain parts with mechanical performances directly comparable with those of wrought titanium. Sponge powder shows similar behaviour to HDH powder in terms of compaction, microstructural features, densification and relative density. Nevertheless, its mechanical properties are significantly affected by its greater tendency towards interstitials pick-up.

\section{Acknowledgements}

The authors want to acknowledge the financial support from the Spanish Ministry of Science through the R\&D Projects MAT2009-14547-C02-02 and MAT2009-14448-C02-02 and from Regional Government of Madrid through the ESTRUMAT (S2009/MAT-1585) project. 


\section{References}

[1] Donachie MJ. Titanium. A Technical Guide. 2nd Edition ed. Ohio, USA: ASM International; 2000.

[2] Leyens C, Peters M. Titanium and Titanium Alloys. Fundamentals and Applications. Köln, Germany: Wiley-VCH; 2003.

[3] Allen P. Titanium Alloy Development. Advanced Materials \& Processes. 1996;150:35-7.

[4] Froes FH. Titanium - Is the Time Now? JOM. 2004;56:30.

[5] Jackson M, Dring K. Materials Perspective - A Review of Advances in Processing and Metallurgy of Titanium Alloys. Materials Science and Technology. 2006;22:881-7.

[6] Crowley G. How to Extract Low-cost Titanium. Advanced Materials \& Processes. $2003 ; 161: 25-7$

[7] Gerdemann SJ. Titanium Process Technologies. Advanced Materials \& Processes. $2001 ; 159: 41-3$

[8] Peter WH, Blue CA, Scorey CR, Ernst W, McKernan JM, Kiggans JO, et al. Non-melting Processing of "Low-cost" Armstrong Titanium and Titanium Alloy Powders. Proceedings of the Light Metals Technology Conference 2007. Saint-Sauveur, Québec, Canada, 2007.

[9] Lavender CA, Weil KS. Low-cost Titanium Powder for Feedstock. In: FY 2007 Progress Report CPNnl, editor. Automotive Lightweighting Materials: available at: http://www1.eere.energy.gov/vehiclesandfuels/pdfs/lm_07/4_automotive_metalstitanium.pdf; 2007. Last access: January 2014.

[10] Chen GZ, Fray DJ, Farthing TW. Direct Electrochemical Reduction of Titanium Dioxide to Titanium in Molten Calcium Chloride. Nature. 2000;407:361-4.

[11] Metalysis Leads Charge for Change in Titanium Production. Metal Powder Report. 2009;64:6-11.

[12] Sung S-Y, Kim Y-J. Alpha-case Formation Mechanism on Titanium Investment Castings. Materials Science and Engineering: A. 2005;405:173-7. 
[13] Williams DN, Wood RA. Effects of Surface Condition on the Mechanical Properties of Titanium and its Alloys. Battelle Columbus Labs Ohio Metals and Ceramics Information Center; 1971. p. MCIC-71-01.

[14] Froes FH, Gungor MN, Imam MA. Cost-affordable Titanium: The Component Fabrication Perspective. JOM. 2007;59:28-31.

[15] Romig AD, DeHaemer MJ. ASM Handbook vol. 7: Powder Metal Technologies and Applications. Ohio, USA: ASM International; 1998.

[16] Bolzoni L, Ruiz-Navas EM, Gordo E. Flexural Properties, Thermal Conductivity and Electrical Resistivity of Prealloyed and Master Alloy Addition Powder Metallurgy Ti-6Al4V. Materials and Design. 2013;52:888-95.

[17] Li BQ, Wang CY, Lu X. Effect of Pore Structure on the Compressive Property of Porous Ti Produced by Powder Metallurgy Technique. Materials and Design. 2013;50:613-9.

[18] Bolzoni L, Weissgaerber T, Kieback B, Ruiz-Navas EM, Gordo E. Mechanical Behaviour of Pressed and Sintered CP Ti and Ti-6Al-7Nb Alloy Obtained from Master Alloy Addition Powder. Journal of the Mechanical Behavior of Biomedical Materials. 2013;20:14961.

[19] Holm M, Ebel T, Dahms M. Investigations on Ti-6Al-4V with Gadolinium Addition Fabricated by Metal Injection Moulding. Materials and Design. 2013;51:943-8. [20] Bolzoni L, Ruiz-Navas EM, Neubauer E, Gordo E. Inductive Hot-pressing of Titanium and Titanium Alloy Powders. Materials Chemistry and Physics. 2012;131:672-9.

[21] Bolzoni L, Ruiz-Navas EM, Neubauer E, Gordo E. Mechanical Properties and Microstructural Evolution of Vacuum Hot-pressed Titanium and Ti-6Al-7Nb Alloy. Journal of the Mechanical Behavior of Biomedical Materials. 2012;9C:91-9.

[22] Jha N, Mondal DP, Majumdar JD, Badkul A, Jha AK, Khare AK. Highly Porous Open Cell Ti-foam using $\mathrm{NaCl}$ as Temporary Space Holder through Powder Metallurgy Route. Materials and Design. 2013;47:810-9. 
[23] Brandl E, Palm F, Michailov V, Viehweger B, Leyens C. Mechanical Properties of Additive Manufactured Titanium (Ti-6Al-4V) Blocks Deposited by a Solid-state Laser and Wire. Materials and Design. 2011;32:4665-75.

[24] Khan DF, Yin H, Li H, Qu X, Khan M, Ali S, et al. Compaction of Ti-6Al-4V Powder using High Velocity Compaction Technique. Materials and Design. 2013;50:479-83.

[25] Sun J, Yang Y, Wang D. Mechanical Properties of a Ti6Al4V Porous Structure Produced by Selective Laser Melting. Materials and Design. 2013;49:545-52.

[26] Rüdinger K, Piper K-E, Schnecke H, Schüler P. Investigation of Heat-exchange in the Electrode Tip of the Non-consumable Electrode Vacuum Arc Furnace for Melting Titanium. In: Froes FH, Caplan I, editors. Titanium '92: Science and Technology. San Diego, California, 1992. p. $1355-2362$.

[27] Entrekin CH, Harker HR. State of the Art in Electron Beam Melting of Titanium. In: Froes FH, Caplan I, editors. Titanium '92: Science and Technology. San Diego, California1, 992. p. 2339-46.

[28] German RM. Powder Metallurgy Science. 2nd Edition ed. Princeton, USA: MPIF Metal Powder Industries Federation; 1994.

[29] Schatt W, Wieters K-P. Powder Metallurgy. Processing and Materials. Shrewsbury, UK: EPMA - European Powder Metallurgy Association; 1997.

[30] Boyer R, Welsch G, Collings EW. Materials Properties Handbook: Titanium Alloys. In: International A, editor. 2nd ed. Ohio, USA, 1998.

[31] German RM. Powder Metallurgy of Iron and Steel. New York: John Wiley \& Sons, Inc.; 1998.

[32] Finlay WL, Snyder JA. Effects of Three Interstitial Solutes (Nitrogen, Oxygen and Carbon) on the Mechanical Properties of High-purity Alpha Titanium. Journal of Metals $1950 ; 188: 277-86$. 
[33] Jaffee RI, Campbell IE. The Effect of Oxygen, Nitrogen and Hydrogen on Iodide

Refined Titanium. Transactions of the American Institute of Mining and Metallurgical Engineers. 1949;185:646-54.

[34] Jaffee RI, Ogden HR, Maykuth DJ. Alloys of Titanium with Carbon, Oxygen and Nitrogen. Transactions of the American Institute of Mining and Metallurgical Engineers. 1950;188:1261-6.

[35] Ivasishin OM, Anokhin VM, Demidik AN, Savvakin DG. Cost-effective Blended Elemental Powder Metallurgy of Titanium Alloys for Transportation Application. Key Engineering Materials. 2000;188:55-62.

Figure 1. Comparison of the shrinkage induced by sintering for Ti-HDH and Ti-Sponge.

Figure 2. Comparison of the densification parameter (a) and of the relative density (b) for TiHDH and Ti-Sponge sintered samples.

Figure 3. SEM micrographs of Ti-HDH and Ti-Sponge sintered samples, respectively: a) and b) $1250^{\circ} \mathrm{C}$, c) and d) $1300^{\circ} \mathrm{C}$ and e) and f) $1350^{\circ} \mathrm{C}$.

Figure 4. Comparison of the stress-strain curves for Ti-HDH and Ti-Sponge sintered samples $\left(1250^{\circ} \mathrm{C}\right)$.

Figure 5. Comparison of the ultimate tensile strength (left) and strain (right) for Ti-HDH and Ti-Sponge sintered samples. 
Figure 6. Comparison of the Vickers hardness for Ti-HDH and Ti-Sponge sintered samples.

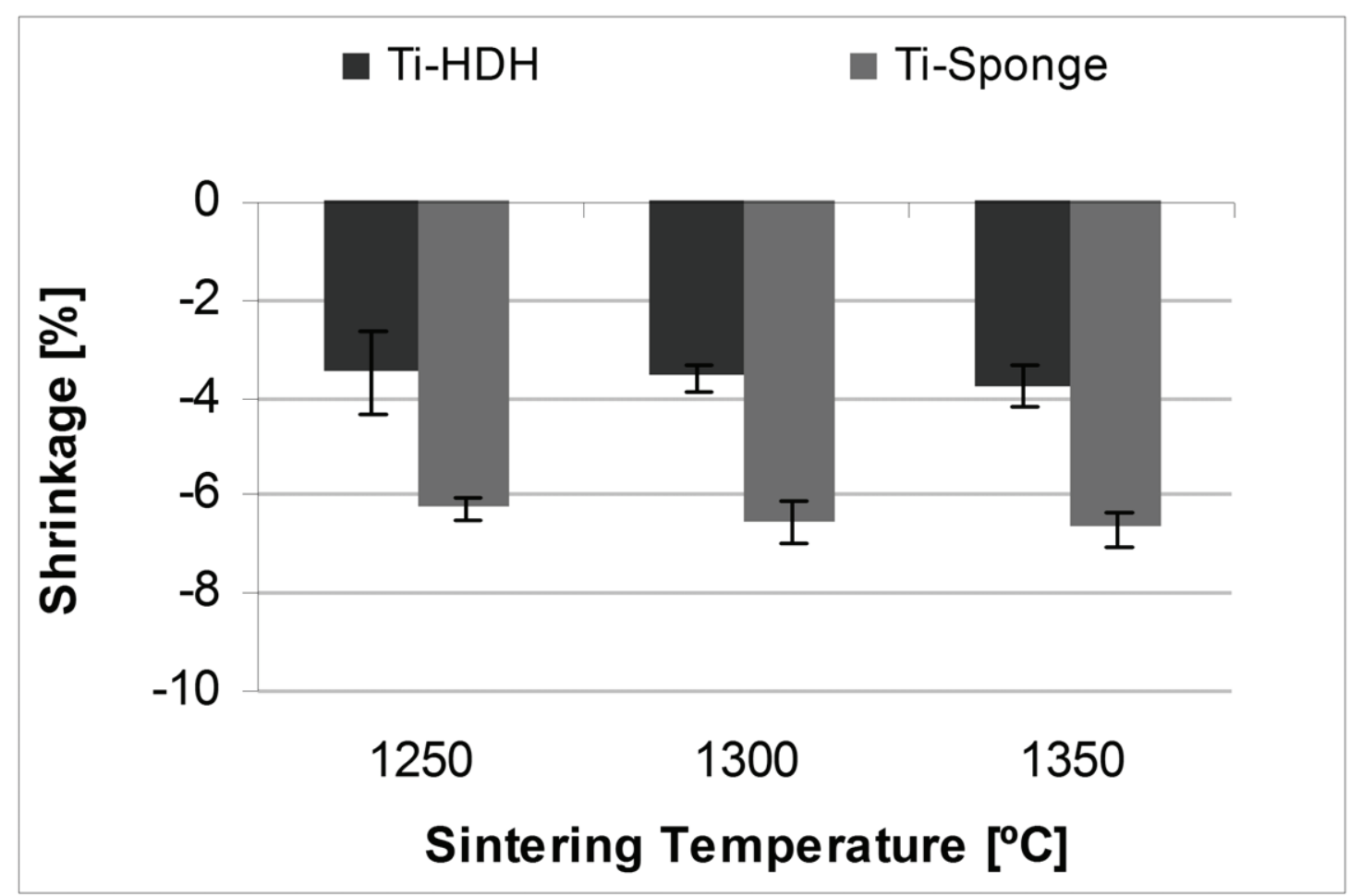



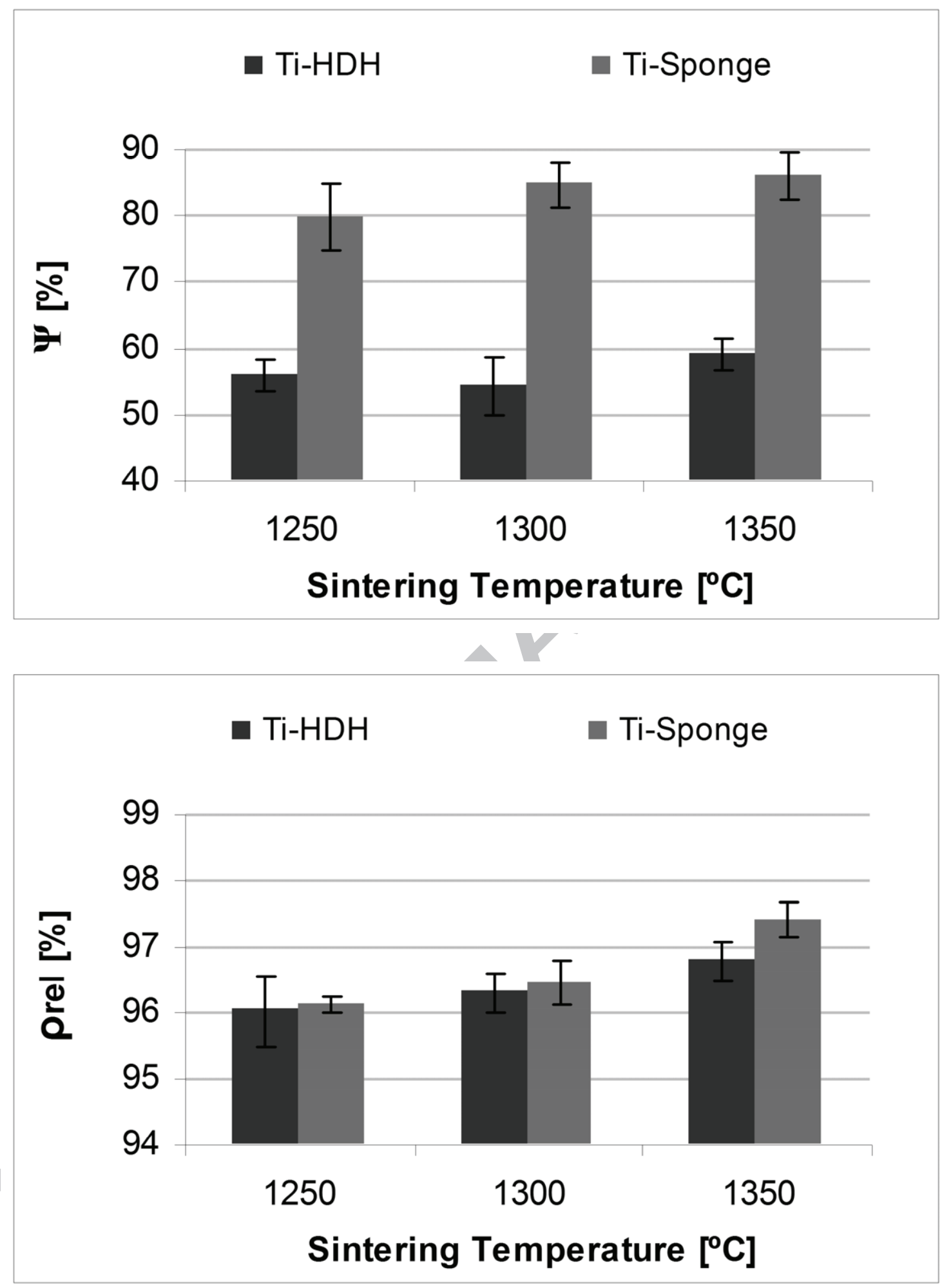

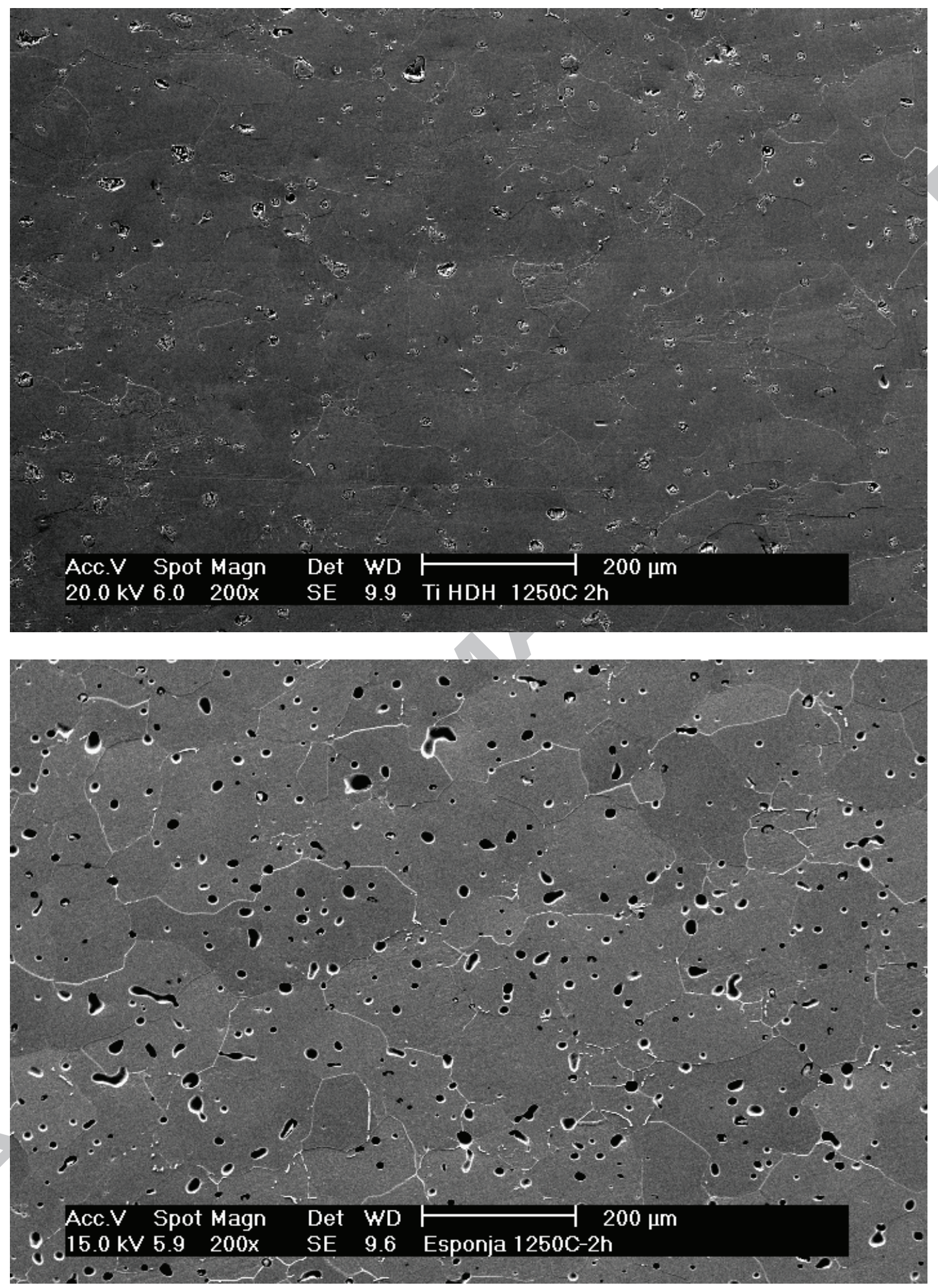

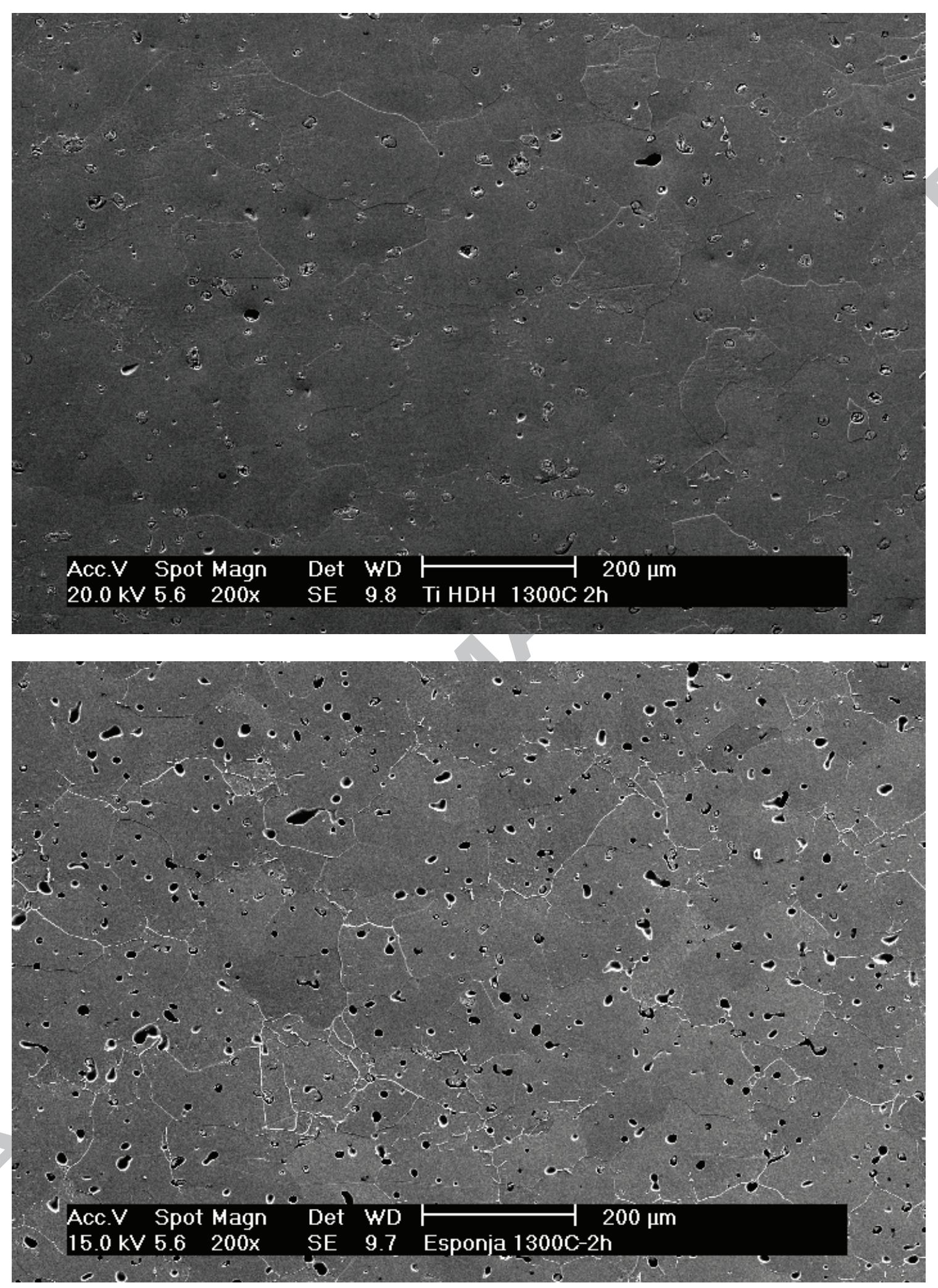

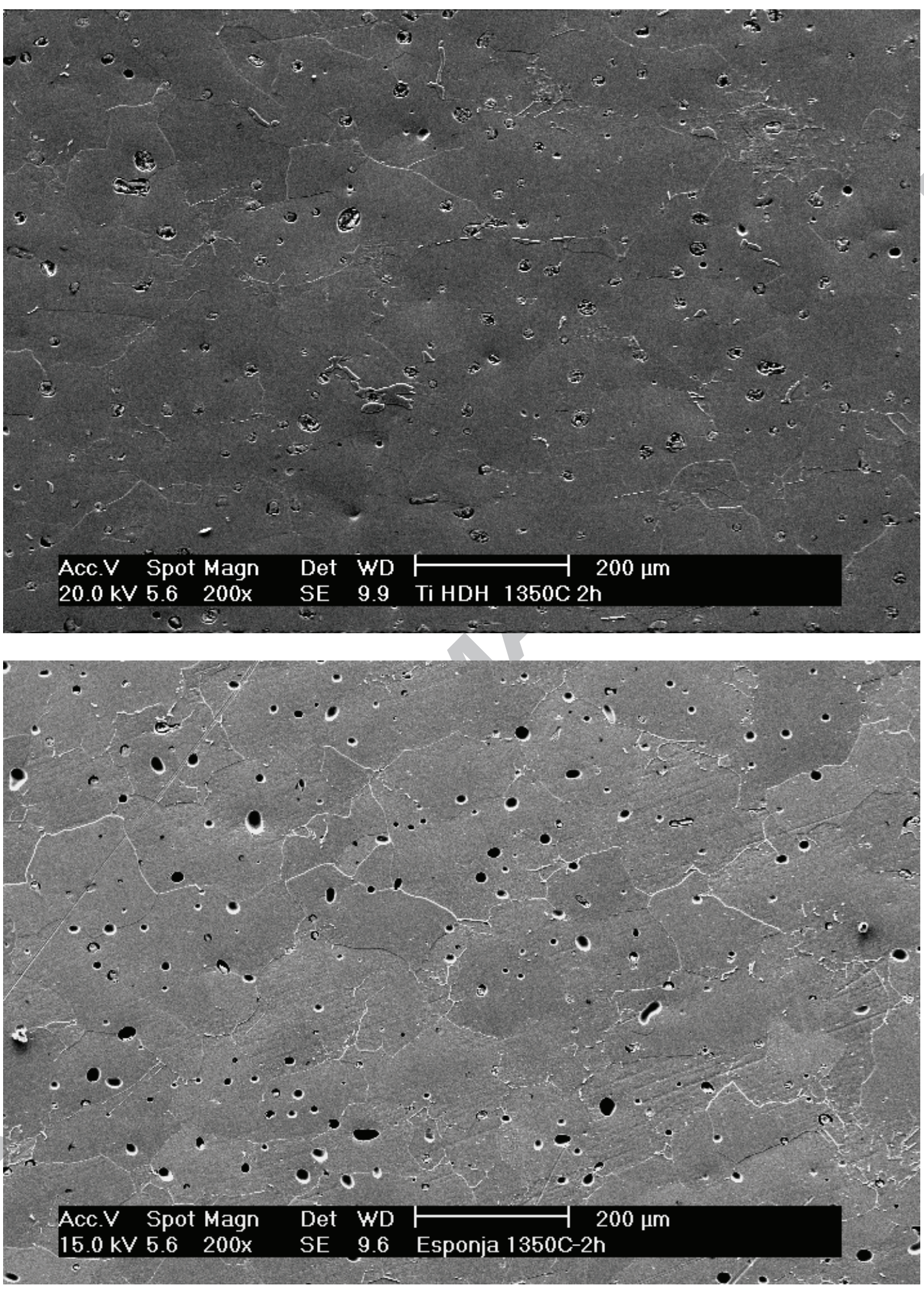


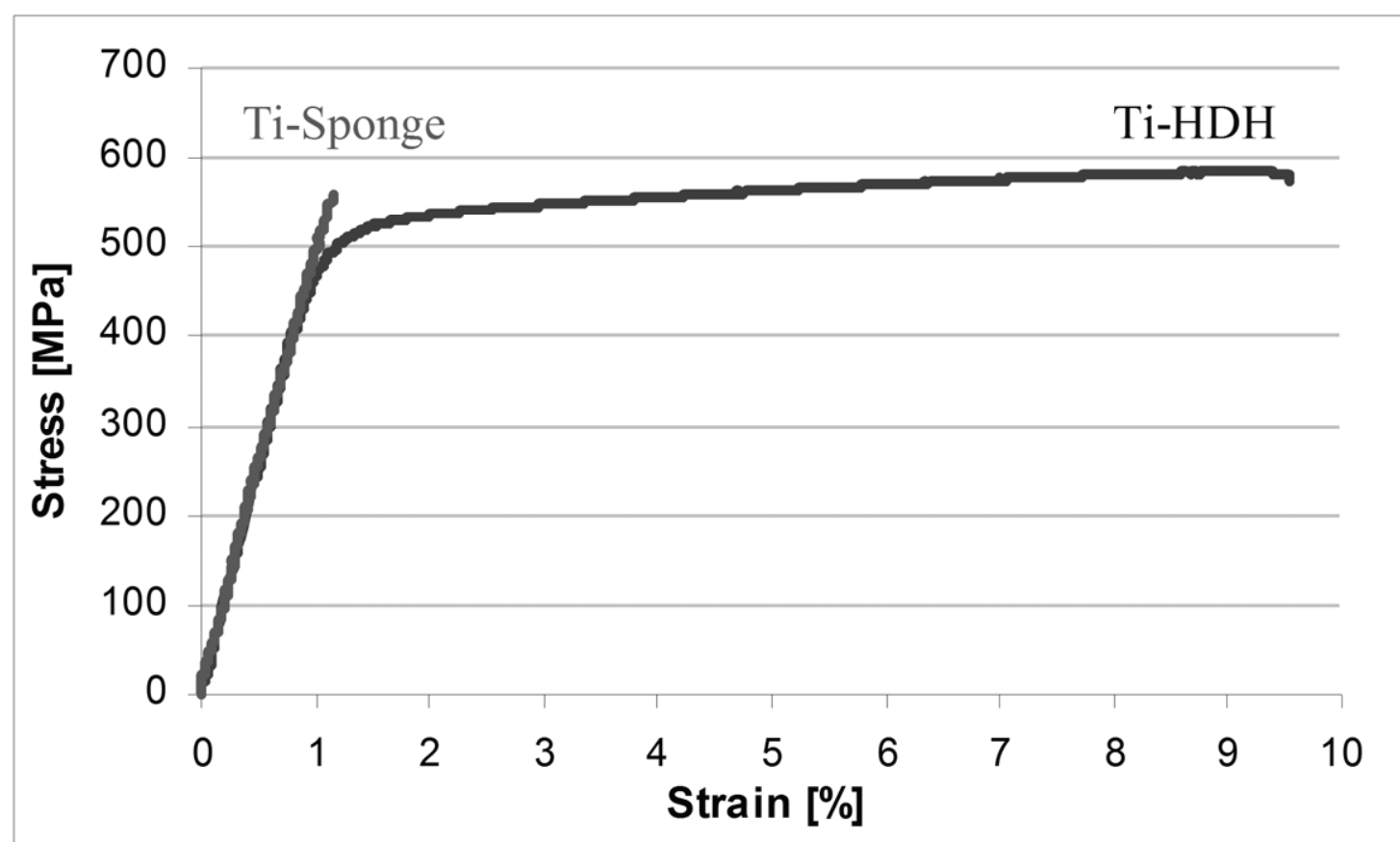




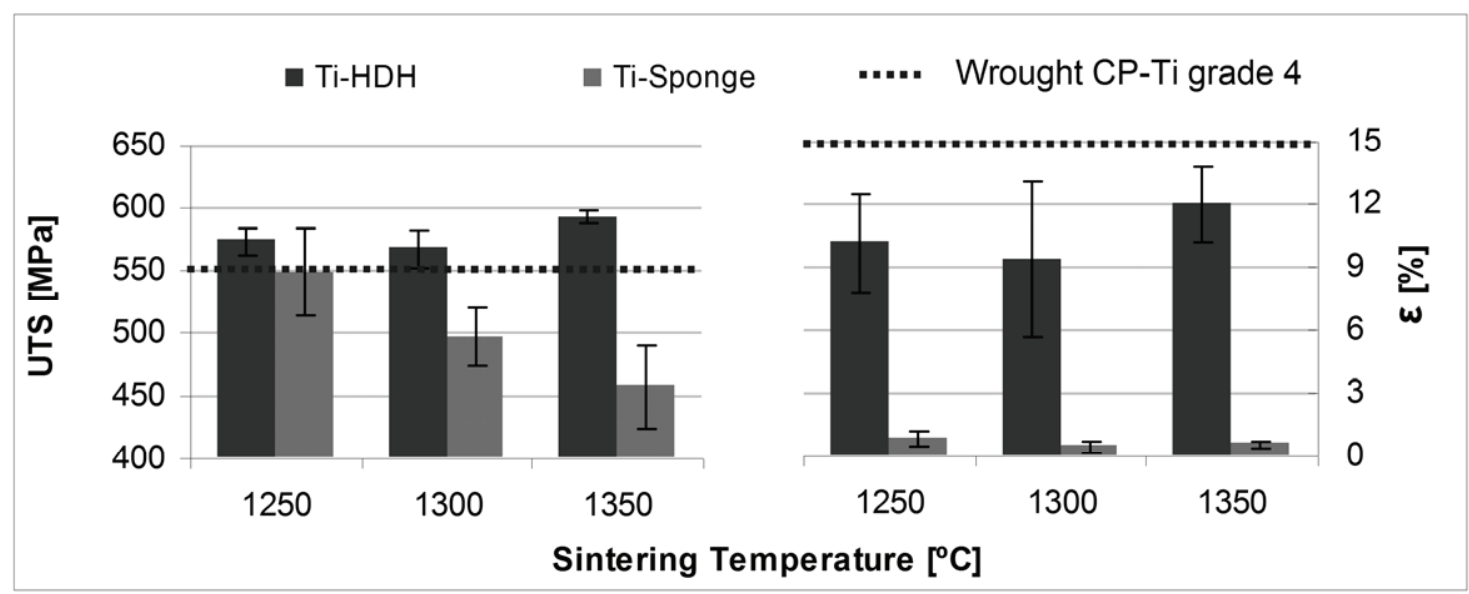




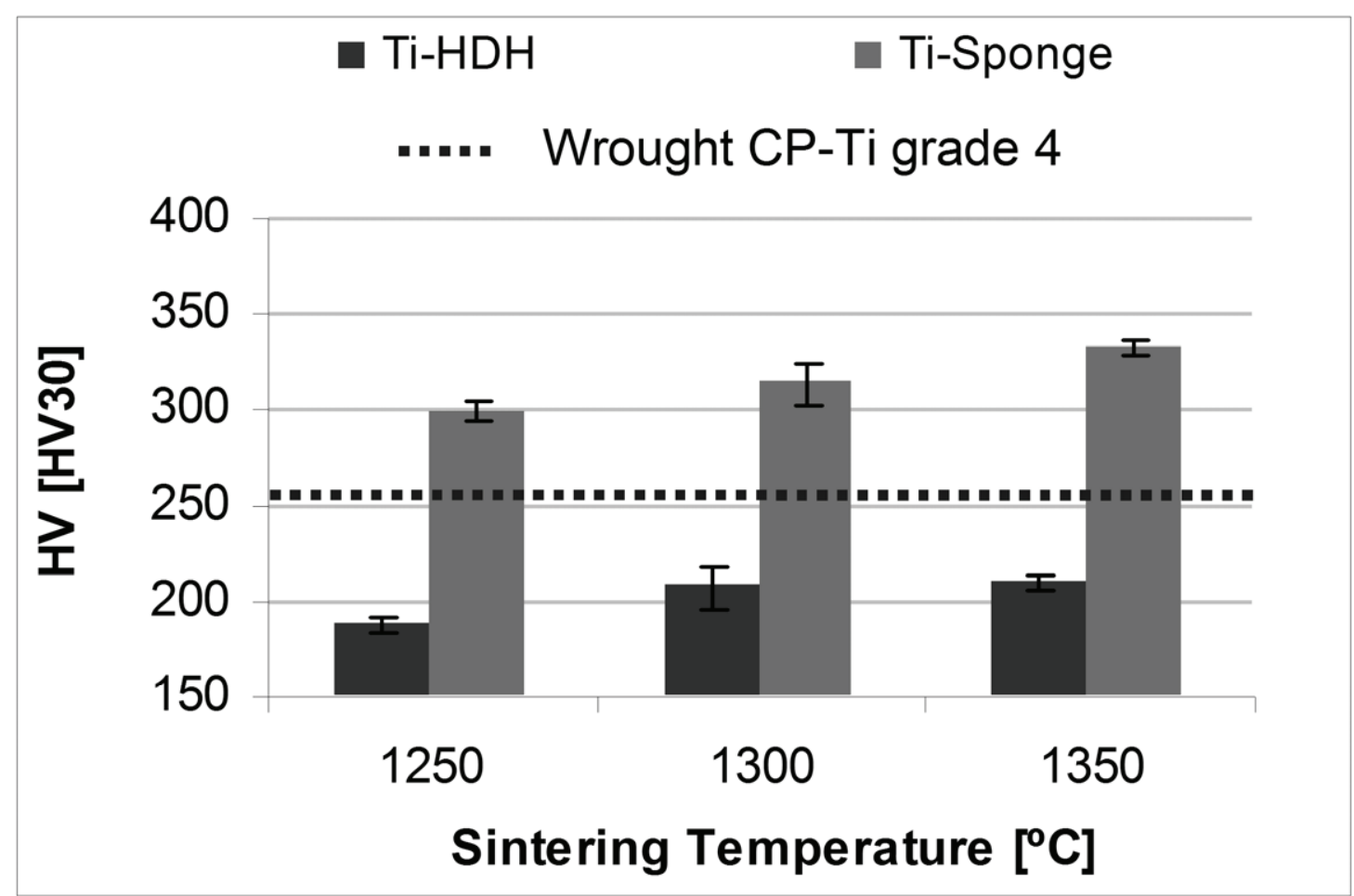


Table 1. Features of the elemental titanium starting powders employed in this study*.

\begin{tabular}{|c|c|c|c|}
\hline \multicolumn{2}{|c|}{ Feature } & Ti-HDH & Ti-Sponge \\
\hline \multicolumn{2}{|c|}{ Production method } & Hydride-dehydride & Kroll's process \\
\hline \multicolumn{2}{|c|}{ Morphology } & Irregular & Sponge \\
\hline \multirow{2}{*}{ Particle size $[\mu m]$} & Mean & 44.25 & 18.46 \\
\hline & Maximum & $<75^{*}$ & $<45^{*}$ \\
\hline \multicolumn{2}{|c|}{ Purity [wt. \%] } & $>99.7 *$ & $>99.7 *$ \\
\hline
\end{tabular}

* Suppliers specifications. 
Table 2. Chemical analysis results for sintered Ti-HDH and Ti-Sponge elemental titanium samples.

\begin{tabular}{|c|c|c|c|c|}
\hline & \multicolumn{2}{|c|}{ Ti-HDH } & \multicolumn{2}{c|}{ Ti-Sponge } \\
\hline \hline & Oxygen [wt.\%] & Nitrogen [wt.\%] & Oxygen [wt.\%] & Nitrogen [wt.\%] \\
\hline \hline Staring powder & $0.27 \pm 0.01$ & $0.016 \pm 0.01$ & $0.44 \pm 0.06$ & $0.039 \pm 0.03$ \\
\hline $1250^{\circ} \mathrm{C}-2 \mathrm{~h}$ & $0.39 \pm 0.03$ & $0.016 \pm 0.02$ & $0.67 \pm 0.03$ & $0.058 \pm 0.07$ \\
\hline $1300^{\circ} \mathrm{C}-2 \mathrm{~h}$ & $0.41 \pm 0.01$ & $0.019 \pm 0.02$ & $0.77 \pm 0.04$ & $0.109 \pm 0.06$ \\
\hline $1350^{\circ} \mathrm{C}-2 \mathrm{~h}$ & $0.40 \pm 0.02$ & $0.017 \pm 0.02$ & $0.80 \pm 0.05$ & $0.121 \pm 0.02$ \\
\hline & & & & \\
\hline Wrought CP-Ti grade 4 & \multicolumn{3}{|c|}{ Oxygen: $0.40 \mathrm{wt} . \%$, Nitrogen: $0.050 \mathrm{wt} . \%$} \\
\hline
\end{tabular}

Table 3. Dynamic Young modulus results for the Ti-HDH sintered samples.

\begin{tabular}{|c|c|c|c|}
\hline Material & Processing conditions & \multicolumn{2}{|c|}{ Dynamic Young modulus [GPa] } \\
\hline \hline \multirow{3}{*}{ Ti-HDH } & $1250^{\circ} \mathrm{C}-2 \mathrm{~h}$ & $103 \pm 1$ & \multirow{2}{*}{ Mean value: } \\
\cline { 2 - 3 } & $1300^{\circ} \mathrm{C}-2 \mathrm{~h}$ & $95 \pm 1$ & $104 \pm 9$ \\
\cline { 2 - 3 } & $1350^{\circ} \mathrm{C}-2 \mathrm{~h}$ & $113 \pm 1$ & \\
\hline \hline
\end{tabular}


> The processing of elemental titanium powders by powder metallurgy is considered. $>$ Hydride-dehydride and sponge are shaped by cold uniaxial press and sinter. $>$ In-depth study of the physical properties, chemical analysis and mechanical behaviour. $>$ Determination of the dynamic elastic modulus by means of ultrasonic measurements. 